\title{
Does the Normative Question about Rationality Rest on a Mistake?
}

\author{
[Preprint; final version forthcoming in Synthese]
}

\section{INTRODUCTION}

The title deliberately echoes H. A. Prichard's famous position on the normativity of morality. The view to be assessed in what follows is that what (Prichard thought) goes for morality, goes for rationality.

The debate over the normativity of rational requirements of coherence has a considerably shorter history compared to the parallel debate over moral requirements. Still, it has been raging particularly fiercely in the past decade or so. Rationality seems to require that our mental attitudes exhibit certain patterns of structural coherence - for example, stated very roughly, the requirement to intend the means we acknowledge are necessary for the ends we intend; the requirement to intend to $V$ if we believe we ought to $V$; and the requirement not to intend to $V$ if we intend to $A$ and believe that we cannot achieve both. ${ }^{2}$ Such requirements set out norms or standards of compliance. That may suffice to demonstrate that they are 'normative' in one sense of the term. In this sense of 'normative', the requirements of etiquette and the requirements of membership in the $\mathrm{Ku} \mathrm{Klux} \mathrm{Klan,} \mathrm{for} \mathrm{instance,} \mathrm{also} \mathrm{count} \mathrm{as} \mathrm{normative}$ requirements. But the contemporary debate over the normativity of rationality concerns a different, stronger sense of 'normative'. This is the sense on which the standards of compliance set out by the requirements are ones we (necessarily) have a reason - indeed, a stringent reason ${ }^{3}$ - to comply with. Moral and prudential requirements are plausibly normative in this latter sense - at least inasmuch as there is necessarily some, though perhaps not stringent, reason to comply with them; requirements of membership in the KKK are not. Are rational requirements of coherence normative in this stronger

\footnotetext{
${ }^{1}$ For their very helpful comments on, and discussions of, earlier drafts of this paper, I am extremely grateful to Hagit Benbaji, Dalia Drai, Alex Gregory, David Horst, Naomi Korem, Jonathan Way, Ruth Weintraub, an audience at the meeting of the European Normativity Network at Humboldt University, and two anonymous referees for this journal.

2 The text provides some examples of requirements of practical coherence; there are plausibly also epistemic requirements of coherence, e.g. that we not believe that $p$ and believe that not- $p$. The focus in what follows will be on practical coherence. There is a rich debate over the precise formulation of some of these requirements, most notably perhaps the requirement of instrumental coherence (see e.g. Broome [2013], Kant [1948], Ross [2009] and Setiya [2007]). But rough formulations will suffice for present purposes. It should be noted also that no suggestion is made here that requirements of rational coherence comprise the whole of what rationality requires.

${ }^{3}$ Having just $a$ reason to comply is taken by many in the debate to be too weak, since such a reason may be outweighed. My thanks to two anonymous referees for stressing the need to clarify this.
} 
sense? This is the so-called 'normative question' about rationality. ${ }^{4}$ Henceforth, whenever the normativity of rationality is discussed, it should be read in the stronger sense of 'normativity'.

Sceptics deny that rationality is normative. One central motivation driving their particular brand of skepticism comes from the so-called 'detachment problem'. Suppose one intends to become chairperson of the most successful pharmaceutical company, and realizes that in order to do so, one must arrange for the chairperson of the main rival company to be assassinated. If the requirement to take the recognizably necessary means to the ends one intends were normative, it would follow that one has a stringent reason to have one's rival assassinated. But one has no such reason (or at least, no such stringent reason), and hence rationality cannot be normative. A standard reply to this problem points out that it rests on a confused picture of the logical structure of rational requirements. The confusion is to assume that the normative operator 'rationality requires that' governs only the consequent, where in fact it governs the entire conditional. Thus, on the allegedly confused, 'narrow-scope' reading of the instrumental requirement, if one intends to become the most successful chairperson, and believes that murdering one's rival is a necessary means for doing so, then one is rationally required to intend to murder one's rival. But, the reply goes, the normative operator in fact takes wide-scope, governing the entire conditional. One is therefore rationally required, either to intend to murder one's rival, or not to intend to become the most successful chairperson, or not to believe that murdering is a necessary means. ${ }^{5}$

The contemporary debate revolves largely around the attempt to assess the prospects of overcoming the detachment problem and other objections to the thought that rational requirements are normative. Comparatively little attention has been paid to the further task of demonstrating that rationality is normative. That is, assuming the wide-scope picture and other resources manage to successfully dispatch the sceptical worries that we have no reason to comply with rational requirements - can it be shown that we do have such reasons? That is the question animating the present discussion.

\footnotetext{
4 The term 'the normative question' originates in Korsgaard (1996), who uses it as a label for the question of what reason we might have to comply with the requirements of morality. Broome (2013) co-opts the label for the parallel question about rationality, and the text follows his usage.

${ }^{5}$ See for example, Bratman (1987): 23-30; Broome (1999): 409-10; and Broome (2004): 29-30.
} 
Attempts to demonstrate the existence of reasons to comply with rational requirements have so far followed a highly inconclusive trajectory. ${ }^{6}$ To see why, notice first that it does not seem credible that there is reason to comply because rationality is intrinsically valuable. As Kolodny says, it is simply 'outlandish that the kind of psychic tidiness that [a rational requirement] enjoins should be set alongside such final ends as pleasure, friendship and knowledge' (Kolodny 2007: 241). A different line of thought aims to show that there is instrumental reason to comply with rational requirements: complying facilitates the achievement of other things one has reason to achieve. But this is an equally unpromising strategy. Recall the above example where one intends to become the most successful chairperson. One would comply with the instrumental requirement if one intended to have one's rival assassinated. But clearly, being rational in this case achieves nothing one has reason to achieve..$^{8}$

Cases of this sort suggest to some the concessive reply on which one may still have reason to be disposed to comply with the requirements; perhaps the disposition to comply does, in the long run, facilitate the achievement of other things one has reason to achieve. However, this reply does not help. For, first, as Kolodny (2008) argues, it is actually quite hard to see how being disposed to comply is supposed to contribute to achieving what one has reason to achieve. And second, the reply is anyway neither here nor there: it fails to vindicate the thought that rationality is normative in the relevant sense, whereby there is always a stringent reason to comply.

\footnotetext{
${ }^{6}$ See Broome (2005), and Kolodny (2005), among many others.

${ }^{7}$ On the wide scope view of the instrumental requirement, one could comply even if one does not intend to have one's rival assassinated; one could instead avoid intending to become the most successful chairperson, or avoid believing that the assassination is a necessary means. And complying with the requirement in at least the former way does arguably achieve something one has reason to achieve, viz. dropping an end one should not intend to pursue. However, there are cases where none of the ways of complying available on a wide scope view will be such that one has reason to perform them. Thus suppose one intends to go on vacation, and believes that one will go only if one intends to call the travel agent. While the wide scope view offers three ways for complying with the instrumental requirement, none of these ways need be such that one has reason to execute them. For one may have some reason to intend to go on vacation, and some reason to call the agent, e.g. because the vacation will be enjoyable. But equally, one could have reason of the same weight not to intend to go, and not to intend to call the agent, e.g. because one's work is piling up. (Assume also that one has no reason to avoid believing that calling the agent is necessary for going on vacation).

${ }^{8}$ Jonathan Way (2012a) formulates and defends a novel alternative to both wide-scope and narrow-scope versions of the instrumental requirement. On Way's 'intermediate-scope' version, if you believe that M-ing is necessary for Eing, then you are rationally required not to [intend to $\mathrm{E}$ and not intend to $\mathrm{M}$ ]. And Way shows that this version of the requirement has an easier time answering the normative question. However, since Way's formulation is not the one typically at issue between Prichardians and their opponents, it will be set aside here. My thanks to an anonymous referee for raising this issue.
} 
This very brief sketch of some of the main failed strategies for vindicating the normativity of rationality leaves room for a further influential strategy that is the focus of the ensuing discussion, under the label Prichardian Quietism. In fact, the failure of the above attempts to show that rationality is normative is entirely in keeping with the Prichardian line. For the latter regards as confused any attempt to identify reasons given by the normative achievements rationality supposedly facilitates or the intrinsic value it possesses. Even if it were true that rationality helps to achieve things one has reason to achieve, or that rationality is intrinsically valuable, still these considerations could not be one's reasons for complying with the requirements of rationality. The only reasons one necessarily has to comply are the ones given by the requirements themselves (in a sense to be explained). ${ }^{9}$

Prichardian Quietism has considerable appeal. It promises to discharge the seemingly intractable task of vindicating the intuitive appearance that rationality is normative. Moreover, it can explain why the task has seemed intractable; it is because solutions have been sought in the wrong place. And it supposedly enjoys an illustrious (if highly contentious) pedigree. However, in what follows it will be argued that the view fails. Three serious flaws it suffers from will be identified. After laying out the Prichardian strategy in a bit more detail in section 2, section 3.1 shows first that the strategy is not plausibly combined with either the narrow-scope or the wide-scope formulations of rational requirements. Then, in 3.2 , the Prichardian view is shown to imply that the reasons to comply with rational requirements are reasons of the wrong kind. And finally, (3.3) it is shown that the Prichardian lacks a crucial component of her explanation, viz. a plausible theory of what constitutes being rationally required to $V$. These problems reveal the Prichardian strategy as unable to explain the normativity of rationality, even if the parallel strategy for explaining the normativity of morality is assumed to succeed. To save words, the problems will be illustrated on the instrumental requirement to take the recognizably necessary means to one's ends. That is a - perhaps the - central requirement of rationality. Consequently, a defense of the normativity of rationality that fails to cover this requirement is fatally flawed. But as will become clear, none of the following problems facing the Prichardian is specific to this or that requirement. Parallel illustrations could be provided of how the problems emerge for other requirements besides the instrumental one.

\footnotetext{
9 A more precise formulation of the Prichardian's claim would read: 'The only reasons one necessarily has to comply, in virtue of being rationally required to comply, are ... '. Since this formulation is rather cumbersome, however, in what follows I shall take the italicized clause as read. I thank an anonymous referee for urging me to clarify this.
} 


\section{PRICHARDIAN QUIETISM}

Prichardian quietism about the normativity of rationality, unpacked in this section, echoes, as already noted, a parallel position famously espoused by Prichard (2002, esp. essays 1 and 2) with respect to the normativity of moral requirements. In order to evaluate the prospects of the isomorphic line of thought about the normativity of rationality, it helps to first spell out Prichard's original argument from which it takes its cue. For the central lesson of what follows is that the analogy with the rational context breaks down at several crucial points.

Prichard was concerned with showing that the normative question about morality is confused because it sets up a false challenge; it asks for a non-moral reason to act morally, but such reasons are specious. Morality provides its own reasons, so any non-moral reasons to be moral (even if they exist), would not answer the normative question. Treating the normative question as posing a sensible, indeed foundational, challenge is the mistake Prichard famously claims to identify in his "Does Moral Philosophy Rest on a Mistake?” (2002, essay 2), (though his quietism is defended in other places as well - e.g. essay 1 of Prichard [2002]). To quickly illustrate Prichard's reasoning, imagine starting to wonder what reason you have to pay back some money you borrowed. The immediate answer is of course that you borrowed the money. And if that answer does not settle the question, it could be backed up with a prima-facie general moral requirement that one ought to pay whatever one borrowed. Now being still unsatisfied with that reply, philosophers raise the normative question in an attempt to uncover a reason that would ground the requirement. They ask: Why ought one pay whatever one borrowed? But this question is specious, according to Prichard. The only reason one necessarily has to repay the debt is the very reason cited by the moral requirement itself, namely that one borrowed the money in the first place. ${ }^{10}$ The demand for a reason that would ground the requirement can only be met by a non-moral reason -- for example, that it would be prudent to avoid any sanctions for not repaying the debt, or even that repaying it would be a

\footnotetext{
${ }^{10}$ Cf. Prichard (2002, p. 4): 'It is not that the principle has no reason but that it includes its reason, the reason becoming explicit when the principle is properly expressed, e.g. my promise to pay someone something, as such ... involves that I ought to pay him'.
} 
good thing. But non-moral reasons to be moral, even if they exist, would not explain the normativity of morality (more on this argument below). ${ }^{11}$

Thus moral requirements are normative, on Prichard's view, but their normativity is not explained by any reasons to be moral that go beyond those cited in the requirements themselves.

Recently, a parallel line of thought has been gaining ground as a way of vindicating the normativity of rational requirements. That the above attempts by Broome, Kolodny, and others to uncover reasons to comply with rational requirements should fail is entirely predictable on this analogous Prichardian line, given that these philosophers are searching for a non-rational reason to be rational. But this failure does not imply that rationality is not normative. For the only reasons to be rational are those cited by the requirements themselves. Two key spokespersons for this view are Nicholas Southwood (2008) and Nadeem Hussain (ms) (The view is also tentatively endorsed by Jonathan Dancy in his [2009: 111-2]; see n. 11 below). Neither Southwood nor Hussain claim that nothing more can be said to explain the normativity of rational requirements beyond pointing out that the requirements contain the reasons for complying with them. But they deny that the (correct) explanation would cite further, independent reasons for complying. Rather, the way to shed further light on the normativity of rationality is to provide 'a philosophical theory of rationality that can do something to explain the normativity of rational requirements by saying what rational requirements are — that can explain how and why they are the kinds of things that are, by their very nature, normative' (Southwood 2008: 19).

The theory of rationality proposed in this spirit by Southwood turns on the idea that rational requirement are relative to a 'first-personal standpoint', and their normativity is a matter of 'honoring our first-personal authority'. A first-personal-relative requirement should not, according to Southwood, be understood as requirements the agent takes herself to be subject to. Rather, they are requirements that the agent is subject to, given her particular first-personal standpoint, viz. the standpoint 'constructed out of [her] particular beliefs, desires, hopes, fears, goals, values, and so on, and relative to which things can go

\footnotetext{
${ }^{11}$ Various replies that have been given to Prichard's original argument will not be discussed here. These include, for example, denying that the goodness of $\mathrm{V}$-ing is a non-moral reason to $\mathrm{V}$; and claiming that complying with moral requirements is constitutive of being a virtuous agent. These and other replies will not be discussed since, as will become apparent, the argument of this paper proceeds by granting for the sake of argument that Prichard's position about moral normativity is defensible, while showing that, even if it is defensible, the analogy with rational normativity breaks down.
} 
well or badly'. Rational requirements set up standards that govern the formation and revision of attitudes. And they can be seen as normative requirements once we recognize that that they are relative to the agent's first-personal standpoint. In fact, Southwood suggests that rational requirements are partly constitutive of having a first-personal standpoint in the first place. Part of what it is to be an agent with a first-personal standpoint 'is to be subject to, and minimally committed to,' rational requirements of coherence. This is so because, according to Southwood, part of what it is to have such a standpoint is to be 'accountable to oneself'. The normativity of rational requirements is therefore explained as 'a matter of honoring our first-personal authority' (2008: 28).

Like Southwood, Hussain also deploys the Prichardian strategy for vindicating the normativity of rationality, including proposing a theory of the nature of rational requirements that can serve to illuminate their normativity in lieu of independent reasons to be rational. But the theory proposed by Hussain is very different from Southwood's. According to Hussain, rational requirements should be understood as governing reasoning and deliberation. Reasoning for Hussain is a conscious and purposive psychological process. Furthermore, it is a process governed by principles that determine which patterns of formation and revision of attitudes count as correct reasoning. And those principles are encoded by the requirements of rationality. There are various processes of transition between mental attitudes that do not count as reasoning at all, e.g. when one forms a belief on the basis of direct perceptual evidence. When such processes occur, or when no process occurs, rational requirements do not apply. Nor do the requirements tell one that one should reason in any given circumstance. Their domain of application is limited to instances of reasoning and deliberation, and their function within that domain is to govern the correct transition between attitudes. They only tell us how we ought to reason. ${ }^{12}$

It is doubtful that either Southwood's or Hussain's particular theories of the nature of rationality manage to shed light on its normativity, as argued below (sec. 3.3). Before then, two general problems with the Prichardian strategy as such will be identified, in sections (3.1) and (3.2), respectively.

\footnotetext{
${ }^{12}$ Dancy (2009) speculates that the kind of normativity rationality has is evaluative: complying with rational requirements is a virtue in agents, even when they do not have a reason to do so. However, as Dancy himself readily admits, this does not yet account for the normativity of rationality. For if rational behavior merits positive evaluation, there must be some explanation of why this is so. What is good about being rational? Having given up on finding a reason to positively evaluate rational agents, Dancy calls on Prichard to support the speculation that rationality may provide its own reasons.
} 


\section{AGAINST PRICHARDIAN QUIETISM}

3.1 First problem: The Prichardian strategy is ill suited to both narrow and wide scope interpretations

To see the first problem, notice that, when applied to the normativity of rational requirements, the strategy is much more naturally tailored to the narrow scope interpretation of those requirements (spelled out in sec. 1 above). Recall that Prichard's original argument turns on the idea that the reasons to comply with moral requirements are those cited by the requirements themselves; for example, one's reason to repay the debt is that one incurred it in the first place. Now when transposed to rational requirements, the idea seems to find a natural correlate in the narrow scope interpretation. Thus it seems prima facie plausible ${ }^{13}$ to suggest that one's reason to e.g. intend the recognizably necessary means to $V$-ing is that one intends to $V$, and believes that the means are necessary. But the narrow-scope interpretation encounters various problems when combined with the thought that rationality is normative, most seriously the detachment problem described above. For this reason, it is widely regarded as an unpromising commitment for any view on which rationality is normative to incur. ${ }^{14}$ In fact, the narrow scope interpretation is standardly wielded by sceptics in their attempt to debunk the normativity of rationality.

This prompts the thought that the wide scope interpretation may prove more promising for the Prichardian. However, the Prichardian idea that the reasons to comply are contained in the requirements is much less naturally coupled with the wide scope than with the narrow scope interpretation. Consider: what could be one's reason to [either not intend to $V$, or intend the recognizably necessary means to $V$ ing, or not believe they are necessary], a reason supposedly given by this wide-scope instrumental requirement? Most wide-scopers deny that rational requirements apply to one in virtue of any particular attitudes one holds; whatever one's actual mental economy, one is required to have the rational pattern of attitudes. Hence, a typical wide-scoping Prichardian would not claim that one's reason to $V$ is that one

\footnotetext{
13 Prima facie plausible though, as we shall see, ultimately untenable.

${ }^{14}$ Schroeder (2009) is a notable exception to the widespread rejection of the narrow-scope view as part of explaining the normativity of rational requirements. Schroeder claims that rational requirements are normative in the sense that they provide subjective reasons to comply, where $A$ has a subjective reason to $V$ just when $A$ would have an objective reason to $V$ if her beliefs were true. Schroeder's view will not be discussed here. This is partly because, when the sceptics the Prichardian is responding to deny that there are reasons to be rational, it is not typically subjective reasons they have in mind.
} 
has some antecedent attitudes which imply that one is rationally required to $V$. Instead, she would suggest that one's reason to $V$ is the very fact that $V$-ing is rationally required (cf. Hussain [ms]).

It is unclear that this suggestion helps, however. For it is far from intuitively obvious why the fact that one is rationally required, e.g. to intend the recognizably necessary means to $V$-ing if one intends to $V$, should be a reason to do so (contrast the platitude that one's reason to repay the debt is that one incurred it, or the suggestion that one's reason to intend the recognizably necessary means is that one intends the end). Considerably more will therefore need to be said by way of demonstrating that this in fact one's reason to comply with the wide-scope requirement. And furthermore, even if more could be said in this vein, it would seem to be importantly out of step with the Prichardian's quietist aspirations to do without further explanation of what reasons there are to be rational. The conceivable ways of filling out an explanation of why the fact that rationality requires $V$-ing is a reason to $V$ seem to appeal to further, non-rational considerations (perhaps complying with the requirements is intrinsically valuable? Perhaps it is one's duty to comply? And so on).

As noted, most wide-scopers contend that rational requirements have unrestricted jurisdiction, applying to all agents, whatever attitudes they happen to hold. Recently, however, the possibility has been raised of wide-scope requirements with restricted jurisdiction. Thus Brunero suggests briefly that widescopers might do well to formulate the instrumental requirement as follows: If one intends to $V$, believes that $M$-ing is necessary to $V$-ing, and does not intend to $M$, then rationality requires that one [either not intend to $V$, or intend to $M$, or not believe that $M$-ing is necessary to $V$-ing] (Brunero 2015: 244). Brunero's formulation may avoid the above problem for standard wide-scopers. After all, it seems natural enough to suggest that one is required to [either not intend to $V$, or intend the recognizably necessary means to $V$-ing, or not believe they are necessary] just because one intends to $V$, recognizes the necessary means, but does not intend to take them.15

However, this formulation is problematic in other ways. First, Brunero's proposal - in contrast to both the standard wide scope and the standard narrow scope views - implies that it is never rationally forbidden to become instrumentally incoherent. For on this proposal, the instrumental requirement applies

\footnotetext{
${ }^{15}$ I am grateful to an anonymous referee for getting me to address Brunero’s proposal.
} 
only to agents who are already incoherent, requiring them to exit their incoherent state. And that is very odd. It would be a bit like suggesting that morality does not forbid acts of stealing, but only requires that stolen goods be returned to their rightful owner. A second serious oddity is that it seems one can never actually comply with Brunero's requirement. Suppose I intend to $E$, believe that $M$-ing is necessary to $E$ ing, and do not intend to $M$. Now if I change one (or more) of these attitudes in an attempt to comply with Brunero's requirement, then I am no longer subject to it. Thus one can never comply with the requirement but at most exit its jurisdiction.

It therefore seems that neither the narrow scope nor the wide scope view are plausible correlates of the Prichardian strategy. ${ }^{16}$ The next section spells out a further serious problem with the Prichardian line, which arises irrespective of whether, or however, this first problem is resolved. The further problem is that both of the above candidates for a Prichardian reason to comply with the instrumental requirement viz. that one intends the end and believes the means are necessary, or that one is rationally required to comply - seem to be reasons of the wrong kind.

\subsection{Second problem: Prichardian reasons are reasons of the wrong kind}

Wrong Kind of Reasons (WKR) are a widely discussed phenomenon in contemporary value theory. ${ }^{17}$ A classic example of a WKR is the pragmatic reason to believe in God proposed by Pascal's famous wager. For another example, suppose an evil demon threatens to kill you unless you admire him, thereby giving you a WKR to admire him. The literature contains various attempts to explain how such WKRs differ from standard, right-kind reasons. To this end, various earmarks of WKRs have been identified. Such earmarks are regarded as distinctive features of WKRs. And these paradigmatic earmarks are

\footnotetext{
${ }^{16}$ Might Southwood's or Hussain's way of developing the Prichardian strategy help with the problem described in this section (as an anonymous referee helpfully inquired)? It might be thought, for example, that being constitutive of one's first-personal standpoint, as Southwood suggests, illuminates the otherwise obscure reason-giving status of rational requirements, which was the problem raised for the wide-scoping Prichardian. However, being constitutive of one's standpoint could not be part of one's reason to comply, on pain of running afoul of the Prichardian's quietist aspirations. And similarly for Hussain's suggestion that rational requirements tell one how to reason. The original obscurity, therefore, remains. Turning briefly to the narrow scope version of the Prichardian strategy, neither Hussain's nor Southwood's proposals seem to relieve bootstrapping-induced anxieties. It still seems highly objectionable to suppose that one could bootstrap reasons to intend silly or wrong acts merely by having certain attitudes - even if those attitudes partly constitute one's first-personal standpoint or conform to rules of correct reasoning. Southwood's and Hussain's proposals are more closely scrutinized in section 3.3 below.

${ }_{17}$ WKRs were identified in the course of debates over the fitting attitude account of value, as they seem to present counterexamples to that account. See e.g. D’Arms and Jacobson (2000): 747, and Schroeder (2010): 26-7.
} 
exhibited by the above candidates for a Prichardian reason to comply with rational requirements, as will now be demonstrated.

One such earmark is that a WKR to have attitude $A$ is given by features of $A$ rather than features of its object. For example, in Kavka’s famous toxin puzzle (1983), an eccentric billionaire offers you $\$ 1 \mathrm{~m}$ to intend to drink an unpleasant poison, whether you actually drink it or not. This gives you a WKR to intend to drink the poison, a reason provided by features of the intention to drink the poison rather than features of drinking it. And the same holds for the different proposals surveyed above of a Prichardian reason to comply with the instrumental requirement. They all cite reasons given by features of the attitudes one would have if one complied - viz., that these are attitudes required by rationality. This is so whether one's reason to intend the necessary means is that one intends the end and recognizes the means are necessary, as the narrow scope version of the Prichardian strategy suggests; or whether one's reason to see to it that one [either intends the means, or does not intend the end, or does not believe the means are necessary] is that rationality requires one to comply, as the wide-scope version suggests.

Another earmark of WKRs concerns the capacity to be motivated by or respond to them. It is typically much harder to respond to WKRs compared to reasons of the right kind (RKR). For example, it is hard to see how one could come to believe in God on the pragmatic grounds given by Pascal's wager, or how you could come to intend to drink the poison on the grounds that it would win you $\$ 1 \mathrm{~m}$ if there is no reason to actually drink it. And it is similarly hard to see how one could come to have the attitude(s) required by instrumental rationality on the grounds that they are rationally required, or on the grounds that one has other attitudes which imply that one is rationally required to comply. ${ }^{18}$ Thus suppose that one intends to have one's business rival assassinated, but realizes there is no reason to actually do so. Taking the narrow scope version first, it is hard to see how one could come to intend the recognizably necessary means of contacting an assassin merely on the grounds that one's attitudes imply that one is rationality required to contact him. Nor is it clear how one could come to see to it that one [intends to contact the assassin if one intends to have the rival assassinated and believes contacting the assassin is necessary] merely on the grounds that this combination is required by the wide-scope requirement. (To be

\footnotetext{
${ }^{18}$ Kolodny argues on the basis of something like the motivational earmark that any reason to be rational would have to be a WKR (or, as he puts it, a 'state-given' reason [Kolodny 2005: 547-551]). More on Kolodny's argument below.
} 
sure, it is not hard to see how one could come to comply by dropping one's intention to have one's rival assassinated on the grounds that there is no reason to have bim assassinated; but that would be responding to an altogether different reason than the one supposedly given by the wide-scope requirement). ${ }^{19}$

A third earmark of WKRs, identified recently by Jonathan Way (2012b), has to do with the distinctive transmission pattern they conform to. Way shows that WKRs do, and RKRs do not, transmit according to the following pattern:

(Wrong Reason) If there is a reason of the wrong kind for attitude A, then the fact that attitude $\mathrm{B}$ facilitates attitude $\mathrm{A}$ is a reason of the wrong kind for attitude $\mathrm{B}$.

For example, in the toxin puzzle, believing that one ought to drink the poison facilitates intending to drink it. And this is indeed, as Wrong Reason predicts, a WKR to believe that one ought to drink the poison. Way also identifies several distinctive transmission patterns of RKRs, for example:

(Right Reason Intention) If there is a reason of the right kind to intend to A, then the fact that Bing facilitates A-ing is a reason of the right kind to intend to B.

If the present earmark is also exhibited by the Prichardian candidates for the reason to be rational, we should expect these reasons to transmit according to Wrong Reason, and to fail to transmit according to Right Reason Intention. What follows is a brief demonstration that this is in fact so. To save words, a

${ }^{19}$ For further evidence of the difficulty to be motivated by reasons internal to rationality, notice how peculiar the following pieces of reasoning seem:

(Narrow) 'I intend to E and believe I won't E unless I intend to M'; 'Rationality requires that I intend to M'; 'So, I'll M'.

(Wide) 'Rationality requires that I intend to $\mathrm{M}$ if I intend to $\mathrm{E}$ and believe I won't $\mathrm{E}$ unless I intend to M'; 'I intend to E, believe I won't E unless I intend to M, but don't intend to M'; 'So, I'll M'.

And contrast the perfectly natural:

(Moral) 'I incurred a debt'; 'morality requires that I repay a debt if I incur it'; 'So, I'll repay the debt'.

Broome (2013: ch. 12) raises, in a different context, several problems for the idea that reasoning could proceed via a higher-order belief about the attitudes required by rationality, as in Narrow and Wide. The structure of the reasoning Broome imagines is different from the one described here; for example, he would probably replace the conclusion with something like 'So, I'll intend to M'. Broome shows that reasoning that followed such higher-order patterns would encounter difficulties over e.g. having to implausibly postulate an intention to intend to M, which would then cause one to intend to $\mathrm{M}$. 
detailed demonstration will be given only for the narrow scope version of the Prichardian internal reason, thought the way to extend it to the wide scope version will be indicated.

Suppose, then, as the narrow scope Prichardian allows, that one's (only) reason to intend to book a ticket to $\mathrm{CA}$ is that one intends to go to $\mathrm{CA}$ and believes that booking a ticket is necessary for going (assume one has no reason to actually go to CA). Suppose further that calling the travel agent facilitates booking a ticket. If the fact that one intends to go to CA and believes that booking is necessary is a RKR to intend to book the ticket, Right Reason Intention predicts that the fact that calling facilitates booking would be a RKR to intend to call. But this prediction fails. For the case is such that one has no reason to book the ticket, since one has no reason to actually go. Hence, the facilitation relation holding between calling and booking does not constitute a RKR to intend to call. Consequently, according to the transmission test, intending to go to CA and believing that booking a ticket is necessary is not a RKR to intend to book a ticket.

It remains to be seen whether one's reason to intend to book a ticket does transmit according to the Wrong Reason pattern. Suppose, then, as seems plausible, that believing one ought to book a ticket facilitates intending to book a ticket. If the fact that one intends to go to CA and believes booking is necessary is a WKR to intend to book, Wrong Reason predicts the following: the fact that believing one ought to book facilitates intending to book would be a WKR to believe that one ought to book. And this prediction is indeed confirmed: that believing one ought to book facilitates intending to book is a pragmatic, not evidential, reason for believing.

The above demonstrates that the Prichardian reason to comply with the instrumental requirement in its narrow scope version conforms to the distinctive transmission pattern of WKRs, and to it alone. A parallel demonstration could be given for the wide scope version, by substituting 'seeing to it that one either intends to book a ticket to CA, or does not intend to go to CA, or does not believe that intending to book is necessary for going to CA' for 'intending to book a ticket to CA' as what one supposedly has reason to do. There seems no need to also replace the relata of the facilitation relation in the original example. For if believing one ought to book a ticket facilitates intending to book, then it also facilitates [either intending to book, or not intending to go to CA, or not believing that intending to book is necessary for going to $\mathrm{CA}$ ], precisely because it facilitates the first disjunct. The argument that Prichardian 
wide-scope reasons conform to Wrong Reason will then go through: that believing one ought to book facilitates [either intending to book, or not intending to go to CA, or ...] is a WKR for believing. ${ }^{20}$

Combining this result about the transmission of the possible Prichardian reasons with the presence of the two other earmarks of WKRs described earlier - viz., the motivational earmark, and the reasons being given by features of the attitudes rather than the objects - strongly suggests that the Prichardian's proposals should be classified as WKRs. This would be an extremely uncomfortable outcome for the Prichardian. For one thing, several philosophers argue that WKRs are actually not reasons at all. ${ }^{21}$ But there is actually no need to settle whether WKRs are or are not genuine reasons in order to acknowledge the problem facing the Prichardian. However that question is settled, it would clearly be an empty achievement to vindicate the normativity of rationality by showing that it provides merely WKRs. ${ }^{22}$ This marks an important disanalogy with Prichard's own position about morality, which stands on much better grounds here: the reasons to be moral suggested by Prichard's view are clearly RKRs.

One might object (as an anonymous referee pointed out) that there is no indication that only Prichardian Quietism implies that reasons to be rational are WKRs. And if other views carry the same problematic implication, PQ would be no worse off by comparison. Now, it is impossible of course to anticipate all the various possible accounts of the reasons we have to be rational and examine whether they are vulnerable to the problem of WKRs. But at least the main candidates discussed in the literature

\footnotetext{
${ }^{20}$ Readers not convinced that the facilitation-relation cited in the text works for the wide-scope requirement should substitute "believing that one ought to [either book, or not intend to go to CA, or not believe that intending to book is necessary for going to CA]' for 'believing that one ought to book'. It is somewhat less clear what could replace the facilitation relation in demonstrating that Prichardian wide-scope reasons do not conform to Right Reason Intention. This is because the latter is a transmission pattern for reasons to intend, not reasons to [intend to $M$ or not intend to $E$ or not believe intending to $M$ is necessary for $E$-ing]. This may involve a modified transmission pattern. But if Right Reason Intention extends to cover such combinations of attitudes, and assuming that calling facilitates [either booking, or not going to CA, or not believing that booking is necessary] by facilitating booking, then the substitution would be straightforward.

${ }^{21}$ See Gibbard (1990); Kelly (2002): Kolodny (2005) Owens (2000); Parfit (2001) and (2011), chap. 2 \& appendix A; Persson (2007); Pink (1996); Shah (2006) and (2008); Skorupski (2010); and Way (2012b). As noted in passing above, Kolodny argues that 'there are no reasons in general to comply with rational requirements', since any reason to comply with rational requirements would have to be a WKR (2005: 551). Kolodny takes something like the motivational earmark to show that the fact that rationality requires compliance is a WKR. And since WKRs are not reasons, there can be no reasons to comply. Kolodny's argument does not establish that any reason to comply with rational requirements would be a WKR, since not any such possible reason would be given by the fact that rationality requires compliance. (To be fair, Kolodny has different objections to alternative suggestions for what the reason might be). And he is anyway only committed to the claim that WKRs for belief are not in fact reasons, so that only when compliance involves belief, there are no reasons to comply.

${ }^{22}$ Prichard's position is often glossed as complaining that replies to the normative question about morality are bound to identify reasons of the wrong kind. There is therefore some irony in the result that Prichardians about rationality are guilty of a similar mistake to the one Prichard himself was anxious to forestall - even though, of course, it is doubtful that he had in mind the same sense of 'wrong kind' as in the text.
} 
and mentioned above do not seem to be in this position. These include the instrumental accounts discussed by Broome; Schroeder's subjective reasons account (see n. 13); and Way's 'intermediate-scope' account (n. 7). Furthermore, even if some account $\mathrm{X}$ does turn out to imply that reasons to be rational are WKRs, this would be at best a kind of Pyrrhic victory for the Prichardian. For the problem just seems too serious. To concede that our reasons to be rational are WKRs is to concede that they are reasons that may not be capable of motivating us, and that do not bear on the correctness of the response they recommend (Schroeder, 2010). Or worse still, as many have argued (see n. 20) - it would be to concede that they are no reasons at all. Such a concession may leave PQ no worse off than account X, but both would be doomed. The Prichardian is therefore better advised to try to argue that the reasons she proposes are not actually WKRs.

\subsection{Third problem: No plausible constitution theory of rational.-requiredness}

Setting the previous problems to one side, it will now be argued that the putative parallel between the Prichardian treatment of the normative questions about morality and rationality breaks down at another juncture. Prichard's position has importantly more resources at its disposal with which to explicate the normativity of moral requirements compared to the parallel position about rational requirements. Consequently, the latter is explanatorily impoverished, even by the modest standards of its source of inspiration.

To see this, notice an important component of Prichard's view that is often overlooked. Prichard is well known for his rejection of the normative question about morality, as discussed above. What is less well known is that he did not reject the constitution question about morality, viz. the question of what makes it the case that one is morally required to $V$, when one is. In fact, the constitution question is regarded by Prichard not only as perfectly intelligible, but indeed a sensible question to raise. To be sure, Prichard does not find satisfactory the main candidates for a constitution theory of moral rightness. Thus he is sceptical of the thought that either consequentialist or deontological constitution theories manage to fully capture what makes it the case that one is required to perform a morally right act. But Prichard's scepticism on this score turns on substantive objections to the claim that consequentialism or deontology 
formulate sufficient conditions for moral rightness. For example, he denies that the agent-neutral consequences of an act are sufficient to demonstrate its being morally required (seemingly ignoring the possibility of agent-relative consequentialism). And he complains that Kantian theories wholly ignore the goodness of an act as what (partly) constitutes its being required (2002: 2-3).

The above are substantive objections to both deontological and consequentialist theories of what constitutes moral rightness. Their effectiveness or otherwise qua objections is not a concern of the present discussion. What is a present concern is the implication that Prichard does not aim to dismiss the constitution question about moral rightness as unintelligible, nor expose the primary answers to it as confused. Indeed, it seems Prichard is keen to emphasize that consequentialist theories at least capture a significant, if partial, truth about the nature of moral rightness - and, moreover, a truth that is highly relevant to the normativity of morality. He writes:

At best it can only be maintained that there is element of truth in the Utilitarian view that unless we recognized that something which an act will originate is good, we should not recognize that we ought to do the action. Unless we thought knowledge a good thing, it may be urged, we should not think that we ought to tell the truth; unless we thought pain a bad thing, we should not think the infliction of it, without special reason, wrong. (Ibid: 10)

Prichard's prefacing his claim here with 'at best' may suggest agnosticism about the point he goes on to make (as an anonymous referee pointed out). But that does not seem to have been Prichard's attitude. In a very similar passage (2002: 2) he says this: "There does seem, however, an element of truth in [Utilitarianism], viz: that unless the effect of an action were in some way good, there would be no obligation to produce it". (Black and Tiffany [2007], to which I am indebted, share my interpretation of Prichard; so does Dancy [2014].)

The point is important, not least because it renders Prichard's position considerably less radical than it might otherwise seem. It demonstrates that Prichard objects only to the attempt to derive a normative claim from a constitution claim - viz., to derive a claim about what reason one has to comply with moral requirements from a parallel claim about what makes one morally required to comply. In itself, the 
constitution claim expresses a perfectly sensible position. Moreover, the correct constitution claim can bear significantly on the normative claim. On Prichard's view, then, while the constitution of moral rightness cannot provide one's reason to act morally, it does go some way towards explaining why it is that one has reason to act morally, by (partially) explaining why it is that one is required to do so. This reveals Prichard's quietist challenge as much more limited than it may initially seem. There is no reasonsexplanation of the normativity of morality; but there is an (at least partial) explanation which ensures that, and demonstrates why, morality is normative.

Whether the above is ultimately sufficient to render Prichard's position defensible is not a question this paper aims to settle. But it bears noting, as done above, the role played by constitution theories of rightness in Prichard's rejection of the normative question about morality. For this carries an important lesson for the attempt to assess the Prichardian position on the normativity of rationality. If the latter seeks to exploit an isomorphic strategy in a way that enjoys at least as much plausibility as the original, it had better come up with a plausible constitution theory of rational-requiredness, and moreover a theory that illuminates the normativity of rationality.

The point here is not just scholarly: it is not just that, unless Prichardians come up with a plausible constitution theory, their view will be unfaithful to its source of inspiration. That in itself need not be a problem, if the resulting view is plausible in its own right (as an anonymous referee helpfully pointed out). Rather, the point being made bears directly on the independent (im)plausibility of the Prichardian line about rationality. The brief reconstruction of Prichard's own view offered above renders less radical, and hence more palatable, a view that has seemed highly objectionable to many. The claim that there is no further statement of the reasons one has to be moral besides what is stated by the moral requirements themselves is easier to come to terms with once we are assured there is a further explanation of what makes it true that such reasons exist. This provides some illumination of the normative landscape in a way that makes the remaining quietism Prichard advocates easier to live with. Indeed, Hussain and Southwood both seem alive to the need to offer this kind of explanatory relief by proposing their own constitution theories of rational requirements. But they do not seem to achieve their aim, as will be argued in a moment. 
Notice first that the teleological and deontological constitution theories that have so far been considered in the literature do not seem promising. This lesson can be drawn from John Broome's extensive exploration of the possibility that the normativity of rationality might be explained by how it promotes something we have reason to achieve. The examples described above illustrate how Broome is drawn to conclude that this line of thought is hopeless. The scenarios of the chairperson (pp. 2-3) and the vacation planner (p. 3 n. 6) are ones in which complying with what rationally requires achieves nothing the protagonist has reason to achieve. In this way, Broome's argument is designed to cast doubt over the existence of instrumental reasons to comply. But the same arguments serve also to cast parallel doubt over the instrumental value of complying. For these are also examples in which complying would achieve nothing valuable. A similar verdict applies to the thought that what rationality requires is intrinsically valuable or intrinsically choice-worthy. It would no doubt, as Kolodny (2007: 241) says, be 'outlandish' to suggest that one's reason to comply is given by the intrinsic value or choice-worthiness of rationality. And this is so precisely because it is outlandish that complying should be regarded as intrinsically valuable or choice-worthy.

Appealing to teleological or deontological constitution theories of rational-requiredness in order to illuminate the normativity of rationality would therefore be highly implausible moves on the Prichardian's part. But perhaps this result is neither surprising nor debilitating. Perhaps the adequate constitution theory should anyway not be expected to appeal to the notions of value or choice-worthiness. For the latter are essentially moral notions, and hence specifically suited for explaining the constitution of moral rightness. By the same token, we should expect essentially rational notions to be up for explaining the constitution of rational-requiredness. Something like this thought may be driving Hussain's and Southwood's respective accounts of what rationality consists in, described above (pp. 6-7). Perhaps both can and should be read as providing constitution theories of rational requiredness, couched in terms sufficiently close to rationality (first-personal standpoint, reasoning) as to be naturally able to explain its nature. And these constitution theories could then be used to shed light on the normativity of rationality. That would restore the parallel with Prichard's strategy with respect to the normativity of morality.

However, there are problems with seeing how either Southwood's or Hussain's theory is meant to achieve this. Start with Southwood. Recall that on Southwood's view, the requirements of rationality are 
ones agents are subject to, given their particular first-personal standpoint. This idea is no doubt very plausible. Indeed, as Broome (2008: 98) notes, relativity to a standpoint seems to be a feature that rational requirements wear on their sleeve; they are, after all, conditional on attitudes the agent has. A further crucial point for Southwood, also noted above, is that being subject to standpoint-relative rational requirements is partly constitutive of having a standpoint in the first place. ${ }^{23}$ With this constitution claim in hand, Southwood proposes that we can see how his constitution theory of rationality serves to explain its normativity: it explains it as a matter of 'honoring our first-personal authority' (2008: 28).

At this point it is fair to wonder whether this actually contributes to seeing the requirements as normative. Southwood seems to offer little more than materials for a reformulation of the question the Prichardian was meant to (at least partially) explain, viz. what makes it the case that one is required to comply? Glossing the claim that rational requirements are standpoint-relative as the claim that they are conditional on one's attitudes, and understanding their presumed 'authority' as first-personal, the question becomes: what makes it the case that one is required to honor the authority of one's standpoint? This question is no less elusive. Southwood's remarks do not significantly advance our understanding of the nature of rational requirements, and consequently do not illuminate its normativity.

Hussain's picture of rational requirements is, as pointed out above, very different from Southwood's. But it, too, fails to put forward a constitution theory capable of illuminating the normativity of rationality. Recall that Hussain takes rational requirements to govern reasoning and deliberation. On his view, rational requirements tell us how we ought to reason when we do, by encoding the correct rules of this activity. As such, the domain of application of rational requirements is limited. They do not govern psychological processes of transition between attitudes that do no constitute reasoning, e.g. forming beliefs on the basis of perceptual evidence. And they do not tell us that we ought to reason. Thus cases where it seems one ought to violate some rational requirement, e.g. because doing so would guarantee that some horrible war is prevented, do not demonstrate the rationality is not normative, nor that it only

\footnotetext{
${ }^{23}$ More precisely, Southwood claims that it is constitutive of having a standpoint that one be 'subject to, and minimally committed to,' rational requirements (2008: 27; emphasis added). This raises another potential problem with Southwood's position. For the idea of being minimally committed may seem at best to ground a disposition to comply. But, as noted above, and as Southwood himself concedes, the normativity of rationality is presumed to be stronger than that. Rationality is intuitively presumed to be normative in the sense of providing reason, not merely to be disposed to comply, but to always comply.
} 
provides pro tanto reasons to comply. For in such cases, one simply ought not reason. And when one ought not reason, the requirements of rationality fail to apply.

This reveals a first problem with seeing Hussain's picture as a constitution theory of rationalrequiredness that can illuminate the normativity of the requirements. The problem is that on Hussain's picture, rationality seems to be at best contingently normative. In such cases where e.g. violating a requirement would prevent a war, one is not required to comply, and hence trivially one also has no reason to comply. The upshot is at best a rather weak sense of normativity - certainly weaker than the necessary normativity of moral or prudential requirements, for example.

But there is a further, more basic problem. It is that Hussain's picture is simply implausible on its face. Intuitively, violations of rational requirements are possible and indeed widespread even when one has not reasoned. For example, one may fail to put together the facts that together imply that one is violating a requirement, e.g. the fact that one intends to $E$, believes that one will not $E$ unless one intends to $M$, but does not intend to $M$. On Hussain's picture, rationality settles how reasoning should proceed but not whether it should take place at all. One will therefore not be considered irrational in this case. And that is not credible.

Finally, notice a related problem. Suppose one reasons incorrectly, i.e. in accordance with a rule not encoded by a rational requirement. For example, from the premises 'I intend to $E$ ' and 'I believe that I will not $E$ unless I intend to $M$ ', one concludes 'So, I'll desire to $M$ '. However, due to some psychological quirk (or by applying a further incorrect rule) one then reaches the further conclusion 'So, I'll $M$ ', thereby forming an intention to $M$. One then has the attitudes required by rationality. But it seems Hussain is committed to denying that one has complied with the requirement, since one's reasoning fails to follow the correct rules.

Hussain might respond to this objection (as an anonymous referee helpfully pointed out) by conceding that the agent in the example complies with the instrumental requirement while insisting that she is not entirely rational because she violates a basing prohibition against basing an intention to $M$ on a 
desire to $M .{ }^{24}$ But this move only seems to highlight the difficulty with construing rational requirements other than the basing prohibitions as governing correct reasoning. For all the work of governing reasoning would then seem to be done by the basing rules. If it is conceded that one may come to comply with the instrumental requirement without doing any reasoning at all, or by doing incorrect reasoning, it becomes obscure why we should think of that requirement as applying only when one is reasoning.

It seems, then, that all the main proposals for a constitution theory of what it is to be rationally required to $V$ which the Prichardian may wish to appeal to are ill-suited to the task. They are either plausible enough in themselves but fail to illuminate the normativity of rationality, as in the case of Southwood's theory of rational requirements as standpoint-relative requirements that partly constitute one's standpoint; or else they are simply implausible qua constitution theories, as in the case of teleological and deontological theories; or again, they are both implausible in themselves as theories of rationality, and also fail to illuminate the normativity of rationality, as in the case of Hussain's theory of rational requirements as rules of correct reasoning.

No proof has been offered that the above exhausts the possible alternatives available to the Prichardian. But the natural proposals that suggest themselves, and those that have been suggested by Prichadians, have all been surveyed and found wanting. And until a better constitution theory surfaces, this warrants the conclusion that Prichardians are without a plausible constitution theory, which is a crucial component of Prichard's original strategy for vindicating the normativity of morality. It is therefore hard to see the Prichardian about rationality as doing something isomorphic to her source of inspiration.

\section{References}

Black, Sam and Tiffany, Evan (2007), "Introduction: Moral Philosophy Does Not Rest on a Mistake: Reasons to be Moral Revisited", Canadian Journal of Philosophy 37 (Supplement): 7-40.

Bratman, Michael (1987), Intentions, Plans, and Practical Reason (Harvard Univerity Press).

Broome, John (2013), Rationality through Reasoning (Blackwell).

Broome, John (2008), "Reply to Southwood, Kearns and star, and Cullity", Ethics 119: 96-108.

\footnotetext{
${ }^{24}$ See Broome (2013, section 10.4) for the idea of basing prohibitions. Broome also discusses basing permissions.
} 
Broome, John (2005), “Does Rationality Give Us Reasons?”, Philosophical Issues 15: 321-337.

Broome, John (2004), "Reasons", in Reason and Value: Themes from the Moral Philosophy of Joseph Raz, eds. R. J. Wallace, M. Smith, S. Scheffler, and P. Pettit (Oxford University Press): 28-55.

Broome, John (1999), "Normative Requirements”, Ratio 12: 398-419.

Brunero, John (2015), "Review of Mark Schroeder's 'Explaining the Reasons We Share' “, Ethics 126: 238244

Dancy, Jonathan (2014). "Harold Arthur Prichard", The Stanford Encyclopedia of Pbilosophy, ed. Edward N.

Zalta, URL $=$ http://plato.stanford.edu/archives/spr2014/entries/prichard/>.

Dancy, Jonathan (2009), "Rationality and Reasons", in Spheres of Reason, ed. S. Robertson (Oxford

University Press): 93-112.

D’Arms, Justin, and Jacobson, Daniel (2000), "Sentiment and Value”, Ethics 110: 722-48.

Gibbard, Allan (1990), Wise Choices, Apt Feelings (Harvard University Press).

Hussain, Nadeem (ms), The Requirements of Rationality, Unpublished manuscript.

Kant, Immanuel (1948), Groundwork of the Metaphysic of Morals, translated by H. J. Paton (Hutchinson)

Kavka, Gregory (1983), 'The toxin puzzle', Analysis 43: 33-6.

Kelly, Thomas (2002), "The Rationality of Belief and Some Other Propositional Attitudes", Philosophical Studies 90: 163-96.

Kolodny, Niko (2008), "Why be Disposed to be Coherent?” Ethics 118: 437-463.

Kolodny, Niko (2007), “How Does Coherence Matter?”, Proceedings of the Aristotelian Society 107: 229-263.

Kolodny, Niko (2005), "Why be Rational?”, Mind 114: 509-63.

Korsgaard, Christine M. (1996), The Sources of Normativity (Cambridge University Press).

Owens, David (2000), Reasons without Freedom (Routledge).

Parfit, Derek (2011), On What Matters (Oxford University Press).

Parfit, Derek (2001), "Rationality and Reasons", in: Exploring Practical Philosophy: From Action to Values, eds.

D. Egonsson, J. Josefsson, B. Petersson and T. Rønnow-Rasmussen (Ashgate): 19-39.

Persson, Ingmar (2007) "Primary and Secondary Reasons", in: Homage à Wlodek: Philosophical Papers

Dedicated to Wlodek Rabinowicz, eds. T. Rønnow-Rasmussen, B. Petersson, J. Josefsson and D. Egonsson

(Lund University)

Pink, Thomas (1996), The Psychology of Freedom (Cambridge: Cambridge University Press)

Prichard, Harold A. (2002), Moral Writings, ed. J. MacAdam (Clarendon Press).

Ross, Jacob (2009), "How to be a Cognitivist about Practical Reason", Oxford Studies in Metaethics Volume 4, ed. Russ Shafer-Landau (Oxford University Press): $243-281$.

Schroeder, Mark (2010), "Value and the Right Kind of Reason", in Oxford Studies in Metaethics, Volume 5 , ed. Russ Shafer-Landau (Oxford University Press): 25-55.

Schroeder, Mark (2009), "Means-End Coherence, Stringency, and Subjective Reasons", Philosophical Studies 43: $223-48$.

Setiya, Kieran (2007), “Cognitivism about Instrumental Reason”, Ethics 117: 647-673.

Shah, Nishi (2006), “A New Argument for Evidentialism”, The Philosophical Quarterly 56: 481-98

Shah, Nishi (2008), “How Action Governs Intention”, Philosophers' Imprint 8.

Skorupski, John (2010), The Domain of Reasons (Oxford University Press).

Southwood, Nicholas (2008), "Vindicating the Normativity of Rationality", Ethics 119: 9-30. 
Way, Jonathan (2012a), "Explaining the Instrumental Principle," Australasian Journal of Philosophy 90: 487-506.

Way, Jonathan (2012b), “Transmission and the Wrong Kind of Reason”, Ethics 122: 489-515. 